\title{
Desenvolvimento medidor de condutividade elétrica de solo por método de quatro pontas.
}

\author{
Del Caro, R. L. C. ; Valli, F. V. ; Rodrigues, J. P. ${ }^{1}$; Batisti, R. N. ${ }^{1}$; Prado, A. R. ${ }^{1}$ \\ 1 Instituto Federal do Espírito Santo, Serra, ES, Brasil.
}

\begin{abstract}
Resumo
Nos dias atuais, os produtores agrícolas vêm enfrentando o grave problema da seca no campo, o que prejudica a produção e a safra do agricultor. Fato que motiva muitos produtores a buscarem por processos de irrigação mais eficiente, tendo como foco a redução do desperdício de água na irrigação solo. Isso pode ser realizado através de um medidor de condutividade elétrica para avaliar a umidade real do solo atuando conjuntamente com um controlador de irrigação, sendo assim possível irrigar apenas as regiões necessárias do solo. Entretanto, os medidores de condutividade elétrica existentes possuem alto custo, o que torna inviável o uso destas tecnologias pelo produtor. Neste trabalho, foi desenvolvido um medidor de condutividade elétrica de solo pelo método de quatro pontas. $O$ medidor possui quatro terminais fixados no solo, dois dos quais são aplicados uma tensão e outros dois que medem a variação da tensão devido à umidade do solo. Utilizaram-se quatro guias metálicas para coletar as informações do solo, que foram analisadas por um microprocessador. Observou-se que o medidor de condutividade elétrica implementado neste trabalho apresentou resultados satisfatórios, sendo viável o uso deste sistema em agricultura de precisão.

Palavras chaves: Condutividade elétrica, Umidade do solo, Agricultura de precisão.
\end{abstract}

\begin{abstract}
Nowadays farmers are facing the problem of drought, which harms the farmer's production and harvest. This fact motivates many producers to search for more efficient irrigation processes that avoid wasting water by avoiding irrigation of soil that is already sufficiently moist. This can be accomplished through an electrical conductivity meter to analyze soil moisture acting in conjunction with an irrigation controller to irrigate only the required soil regions. However, existing electrical conductivity meters have a high cost, which makes the use of this type of technology unfeasible by the producer. In this work, a low cost electrical conductivity meter was developed. The meter has 4 terminals attached to the ground, 2 of which a voltage is applied and another 2 that measure the voltage variation due to soil moisture. Four metal guides and a wooden base were used to collect the soil information, which was analyzed by a microprocessor. It was observed that the electrical conductivity meter implemented in this work presented satisfactory results, being feasible the use of this system in precision agriculture.
\end{abstract}

Keywords : Electrical conductivity, Soil moisture, Precision agriculture.

\section{Introdução}

A agropecuária no Brasil é de extrema importância, pois este é um setor econômico que influência de forma significativa no desenvolvimento do país. Com o cenário de recessão o setor agropecuário elevou a responsabilidade de promover o aumento significativo no PIB nacional. Passando de $21,4 \%$ registrado em 2014 para 23\% em 2015 segundo o balanço feito pela Confederação da Agricultura e Pecuária do Brasil (CNA) [4]. O PIB brasileiro caiu 3,8\% em 2015 passando para $R \$ 5,9$ trilhões, sendo que o único setor que registrou aumento foi o setor agropecuário [3].
Tendo em vista o desenvolvimento tecnológico, um ramo que vem crescendo consideravelmente no país são os estudos na agricultura de precisão que apresentam as perspectivas mais promissoras na proposta de gerenciamento de lavouras otimizadas de insumos o que permite a diminuição nos custos de produção. Técnicas como defensivos agrícolas, aplicação localizada de fertilizantes e novas formas de monitoramento de características do solo, fornecem informações que permitem um melhor gerenciamento das áreas a serem cultivadas [1]. 
Os elevados níveis de produtividade agrícola estão relacionados ao uso intenso de insumos [5]. Diante disso, com a utilização das novas tecnologias para apoio aos agricultores pode-se determinar os tipos, à época, o local e a quantidade exata de insumos a serem aplicados [2]. Podendo assim aumentar a produção, consequentemente reduzindo o custo de produção devido a melhor aplicação dos insumos e agrotóxicos. Portanto há uma melhor conservação e menor impacto ambiental que este solo estará recebendo. Logo, quanto mais se utilizam dessas novas técnicas, haverá uma racionalização do uso de energia na agricultura.

Um exemplo de um poderoso recurso tecnológico existente nos dias de hoje são os medidores de condutividade elétrica, que podem ser usados com finalidade de medir a umidade do solo, ou seja, aliando a irrigação com esse medidor pode ser diminuído o desperdício de água. Nesse trabalho foi criado um medidor de condutividade elétrica via técnica de 4 pontas para a medição da umidade do solo.

\section{Materiais e Métodos}

Na operação do medidor de condutividade elétrica de quatro pontas, foi aplicado uma tensão e uma corrente elétrica nos dois eletrodos externos através de uma fonte, nos eletrodos internos foi realizada a coleta dos dados de tensão, na aquisição dos dados foi utilizando um microcontrolador (Arduino) conectado a um computador pela porta USB, a utilização do software Matlab foi realizado para possibilitar a manipulação dos dados coletados, para isso foi desenvolvido um programa, onde neste será possível coletar diversos dados de tensão e ao mesmo tempo será calculado a resistividade elétrica e sua condutividade elétrica, por fim esses dados são exportados para o Excel.

Um problema que foi encontrado na realização dos testes foi que o sinal de tensão coletado no sistema através dos eletrodos internos, como pode ser observado na Figura 7, oscilava muito, logo foi projetado um filtro RC para eliminar esse problema. Portanto o sinal de tensão apurado, primeiro passava pelo filtro e depois para o Arduino e em seguida para o Matlab. Com propósito de analisar se os valores de tensão coletados pelo Arduino estavam corretos ou não, foi posicionado um multímetro em paralelo com a saída do sinal coletado.

Para que houvesse uma consistência na realização dos ensaios, foi criada uma metodologia para análise e recolhimento dos dados obtidos. Metodologia esta apresentada a seguir:

- Serão coletados dados durante 10 minutos. Durante este tempo serão realizados cinco recolhimentos, ou seja, a cada 2 minutos iremos rodar o programa para coleta dos dados;

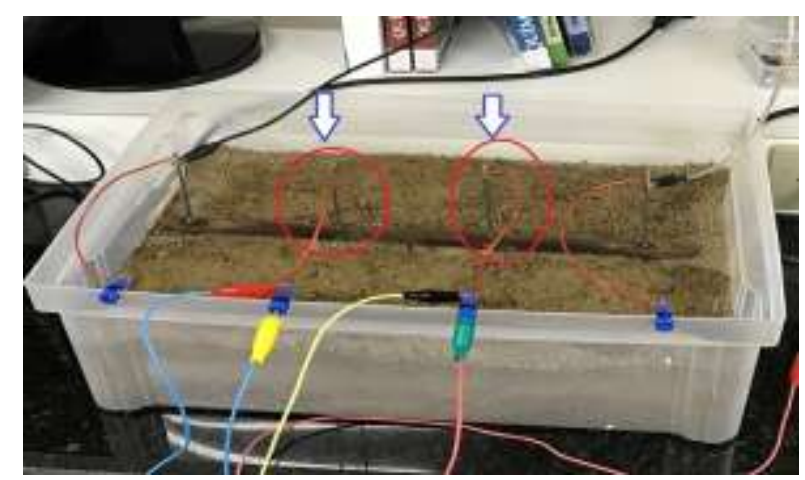

Figura 1 - Eletrodos internos, usados para coletar tensão.

- No programa, o período de amostragem é de 0,01 segundo, e será rodado durante 5 segundos, o que nos dará um total de 500 valores para cada grandeza analisada (tensão, resistividade elétrica e condutividade elétrica) por teste, como serão realizados cinco testes levará um total de 2500 dados para cada um, tensão, resistividade elétrica e condutividade elétrica;

- Foi aplicado ao sistema $18 \mathrm{~V}$ de tensão e uma corrente elétrica de $0,2 \mathrm{~A}$, logo todos os testes realizados serão feitos com esta mesma voltagem;

- Estes testes acima serão realizados com o solo seco, depois com $10 \mathrm{~mL}$ de água borrifados no solo, $30 \mathrm{~mL}$, $60 \mathrm{~mL}$ e por fim com $100 \mathrm{~mL}$ de água.

Os materiais utilizados foram:

- Uma caixa retangular para inserir a terra que será medida a condutividade elétrica.

- Raios de bicicleta cromado para ser o eletrodo que entrara em contato com solo. A primeira consideração estabelecida na escolha do eletrodo a ser usado foi a necessidade de suportar processos corrosivos em ambientes com umidade, por isso foi selecionando aço inox como o melhor material para esse tipo de finalidade.

- Suporte de madeira para fixar os eletrodos.

- Filtro RC, para diminuir os ruídos e oscilações que o sistema detectava.

- Arduino MEGA para realizar a aquisição do sinal coletado.

- $\quad$ Fonte de tensão.

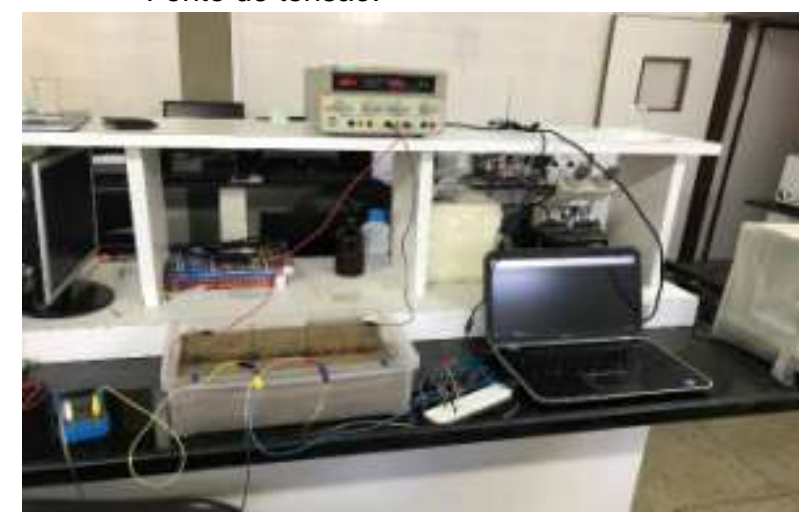

Figura 2 - Medidor de condutividade elétrica montado. 


\section{Resultados e Discussões}

Os resultados obtidos serão apresentados nas figuras a seguir.

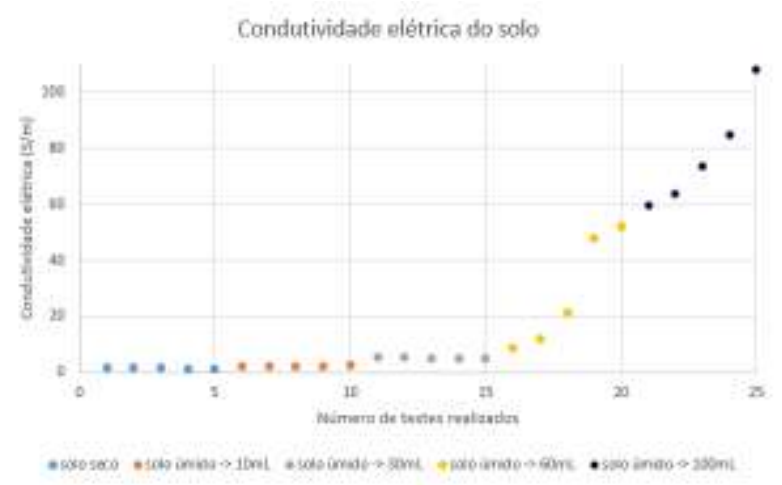

Figura 3 - Gráfico condutividade elétrica do solo.

Pode-se perceber que os valores seguem um padrão, este padrão ocorre devido a metodologia implementada para a medição, apenas ocorrendo um aumento considerável na amostra 18 para a 19 , onde o solo continha $60 \mathrm{~mL}$ de água, a explicação para este comportamento se dá ao fato de com a grande quantidade de água que o sistema está utilizando e a um tempo consideravelmente alto para coletar os dados a água adentrou bem profundamente no solo levando a tensão para valores bem baixos e, consequentemente, valores altos de condutividade elétrica. Já da amostra 1 até a de número 15 a variação é bem pequena, isso ocorre porque a quantidade de água é pequena em relação a quantidade de terra no sistema, por ser pouca água ela não consegue adentrar todas as regiões da terra, ficando apenas superficialmente.

A realização dos cinco ensaios e análise das Figuras 3 e a Figura 4, comprovam o funcionamento do medidor de condutividade elétrica, pois com o aumento de água no sistema, segundo estudos e leituras feitos na revisão bibliográfica, os valores de condutividade elétrica também devem aumentar, e foi exatamente isso que aconteceu.

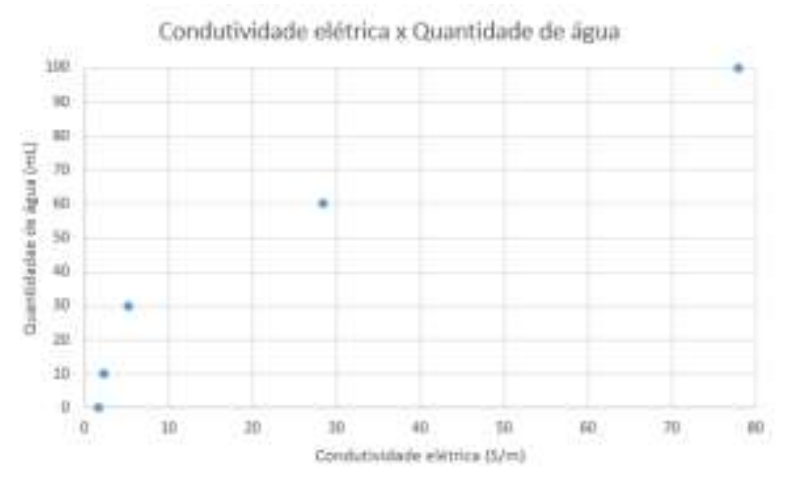

Figura 4 - Gráfico condutividade elétrica x Quantidade de água

\section{Considerações finais}

Neste trabalho foi desenvolvido um medidor de condutividade elétrica de quatro pontas. Segundo os resultados obtidos através do medidor foram satisfatórios e de acordo com outros trabalhos da Literatura. Um dos maiores desafios no desenvolvimento do trabalho, foi como iriam ser recolhidos os dados do solo para depois calcular a condutividade elétrica. A primeira ideia elaborada foi recolher valores de resistência do solo, mas está logo foi descartada devido à variação da resistência do solo ser muito grande, nunca estabilizando em um ponto ideal, posteriormente foram feitas leituras e pesquisas de métodos de medição de condutividade elétrica e se teve a ideia de coletar dados de tensão nos eletrodos internos, primeiramente não foi obtido o sucesso esperado, porque a variação da tensão coletada também era grande, a solução encontrada foi o desenvolvimento de um filtro $\mathrm{RC}$.

\section{Referências}

[1] CASTRO, César Nunes. Definição de unidade de gerenciamento do solo por meio da sua condutividade elétrica e variáveis físico-químicas. 2004. $131 \mathrm{f}$. Dissertação (Mestrado) - Curso de Agronomia, Universidade de São Paulo, Piracicaba, 2004. [2] BEDNORZ, J. G.; MÜLLER, K. A. Z. Phys. B, v. 64, p. 189-193, 1986.

[2] CELINSKI, Vitor George. Desenvolvimento de sensor elétrico de contato e correlações com atributos do solo visando à agricultura de precisão. 2008. $121 \mathrm{f}$. Tese (Doutorado) - Curso de Agronomia, Universidade Estadual Paulista, Botucatu, 2008.

[3] CURY, Anay; CAOLI, Cristiane. PIB do Brasil cai $3,8 \%$ em 2015 e tem pior resultado em 25 anos. 2016. Disponível em: <http://g1.globo.com/economia/noticia/2016/03/pib-dobrasil-cai-38-em-2015.html>. Acesso em: 10 abr. 2017.

[4] PEDUZZI, Pedro. Participação da agropecuária no PIB sobe para 23\% em 2015. 2015. Disponível em: <http://agenciabrasil.ebc.com.br/economia/noticia/2015 -12/participacao-da-agropecuaria-no-pib-sobe-para-23em-2015>. Acesso em: 10 abr. 2017.

[5] PINCELLI, André Luis Sacomano. Desenvolvimento e ensaios de um sistema de mensuração de condutividade elétrica do solo. 2004. 96 f. Dissertação (Mestrado) - Curso de Agronomia, Universidade de São Paulo, Piracicaba, 2004. 